\title{
Field Strain Testing of Transmission Tower Under Wind Load
}

\author{
Weizheng Zhang ${ }^{1,}$, Guojian $\mathrm{Ji}^{1}$, and Yanrun Huang ${ }^{1}$ \\ ${ }^{1}$ Zhengzhou Power Supply Company of the State Grid Henan Electric Power Company, Zhengzhou, \\ Henan 450052, China; \\ axjtuzwz@163.com
}

Keywords: wind load, transmission tower, strain testing, wind-induced vibration.

\begin{abstract}
Detailed accident analysis of a tower failure in Henan was got in this paper. A strain test system was established, location of measuring point was determined at the same time. Long-term monitoring test of the strain value of the $3 \#$ experimental tower in the test base of transmission line in electric power of Henan was accomplished. Analysis of the test data under wind-induced vibration lays the data foundation for preventing the damage of wind and disaster in Henan power system.
\end{abstract}

\section{Introduction}

The safety and stable operation of the power system are affected by inclement weather and natural disasters, which becoming important contributing factors to the power grid failure. According to statistics, 1299 times line dancing occur on 1035 lines involving $35 \mathrm{kV}-1000 \mathrm{kV}$ voltage levels as of 2010, including 707 line dancing trip, causing power outages, leading to direct economic losses about 50 billion and indirect economic losses about 100 billion.

Changing dynamic tension is produced when power line vibrating under the effect of fluctuating wind, and a complex dynamic coupling system is formed among power line and tower. However, due to the lack of more precise analysis methods to guide the design of tower preventing wind, tower damage often occurs in a particular area, resulting tower down accident under strong wind. At present, the transmission tower- dynamic analysis model to calculate the power line system, the wind load model and wind-induced response analysis and the wind tunnel test have been studied by domestic and foreign scholars, but long-term studies on the transmission tower site monitoring carried out less. $^{[2-4]}$

In this paper, the stress concentration of transmission tower under wind-induced vibration is determined by modeling and analysis on finite element software, related strain measurement and analysis on the key positions of tower III in Jianshan real Transmission Line testing base located in Henan. Strain situation of the transmission tower critical nodes are obtained under wind-induced vibration, important data support are provided to the transmission structure design and the implementation of warning systems monitoring wind speed, Contributing to the safe operation of the Henan power grid. ${ }^{[5]}$

\section{Accident investigation of a transmission tower down in Henan}

The evening of July 27, 2007, Henan Kaifeng was hited by thunderstorms, tornadoes, severe convective weather, 21:18, a $500 \mathrm{kV}$ line tower VI crashed. A $500 \mathrm{kV}$ line tripped, phase selection A, RECLOSURE unsuccessful, Forced power transmission unsuccessful. A 500kV line \# 119- \# 124 straight six base tower dumping under strong convective weather was discovered by line patrol.

Figure 1 shows the tower dumping cases: N122 (ZLM-36) tower destruction: bottom sliding bolt of the main tower column was pulled off, tower overall dumping, the 2 Pull disc on the right side of the tower were pulled out to $20 \mathrm{~m}$ outside, no damage to the main column; N123 (ZLM-36) tower destruction: bolt connecting the bottom of main tower column was pulled off, tower overall shift to the left and reverse 8m, tower dumping, no damage to the foundation;N124 (ZB3-45) tower destruction: tower head felled to the ground, Middle of the tower twisted and dumped, no damage to the foundation, line broken. 


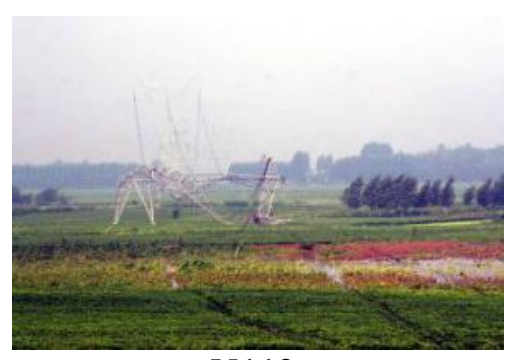

N119

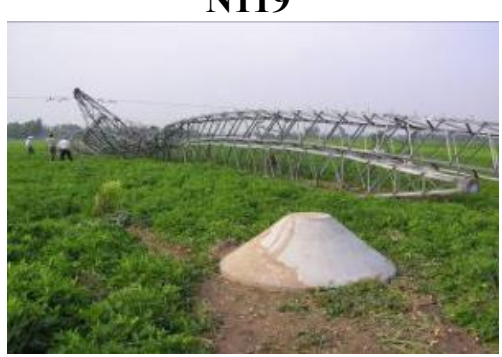

N122

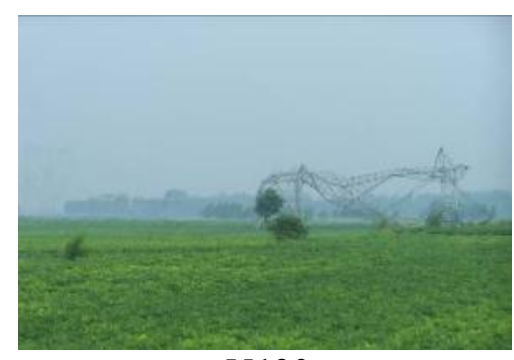

N120

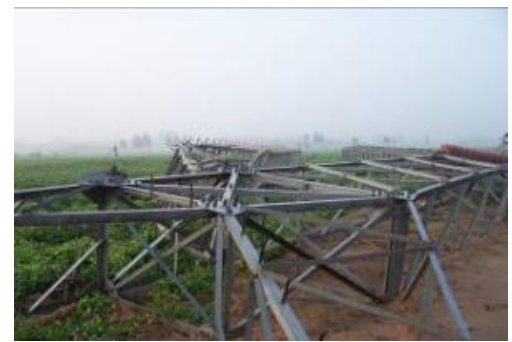

N123

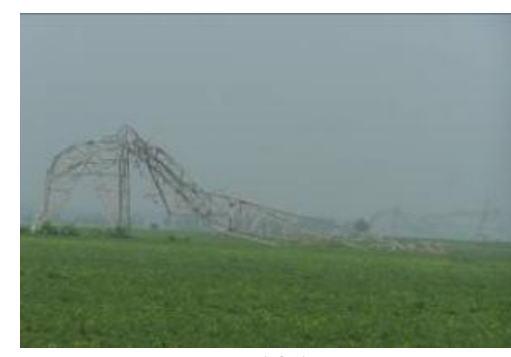

N121

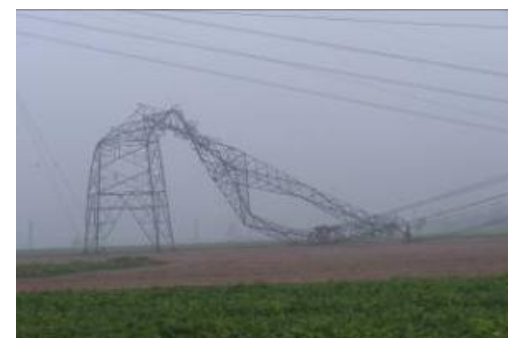

N124

Fig. 1 Damage forms of the transmission towers

The tower down accident is mainly due to the wind load design beyond its limits.

According to the morphological analysis of a line the tower down No. 6 119-124, tower damage working conditions as follows:(1) Dynamic wind loads; (2) Overload when the wind speed exceeds its design; (3) Pull from other adjacent tower when it crashes; (4)Longitudinal unbalanced tension from other adjacent tower when it crashes; (5) A number of possible factors.

\section{Test program}

Three consecutive Henan Province Eagle's Nest true type transmission line test site established $110 \mathrm{kV}-500 \mathrm{kV}$ voltage level, $200 \mathrm{~m} \sim 700 \mathrm{~m}$ span a variety of typical, full-length really Transmission Line $3.7 \mathrm{~km}$ comprehensive test platform, which is the base of natural wind excitation can strain segment long period, large amplitude, high-frequency wave.

$110 \mathrm{kV}-500 \mathrm{kV}$ voltage level, $200 \mathrm{~m} \sim 700 \mathrm{~m}$ typical span, total length of $3.7 \mathrm{~km}$ true type transmission line integrated test platform, are established at Jianshan real Transmission Line testing base located in Henan, long-period strain, large amplitude, high-frequency wave can be achieved under naturally wind excitation.

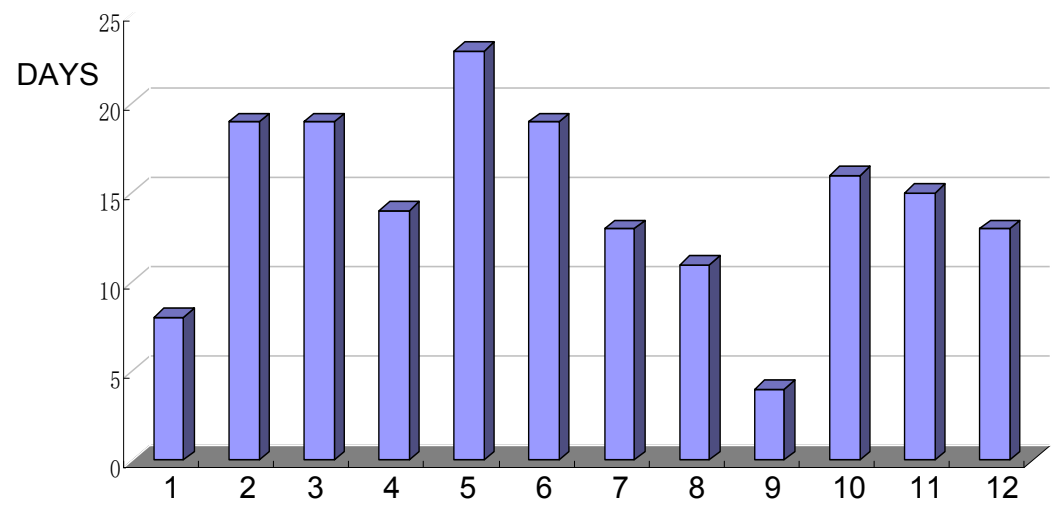

Fig. 2 Line dancing statistics in 2011

Continuous shooting pictures of a particular line dancing on October 8, 2011 are shown in Figure 3, the maximum dancing amplitude is $5 \mathrm{~m}$, frequency of $0.34 \mathrm{~Hz}$.

According to a large number of transmission towers fall accident investigation and transmission towers withstanding wind load through finite element simulation, Maximum stress positions locate the connection between the tower foundation and tower body when the high-voltage transmission towers withstanding wind loads. Weak position under wind load conditions.

The 24 strain gauge layout program is obtained based on the transmission tower structure and the test environmental conditions, as shown in Figure 4. 


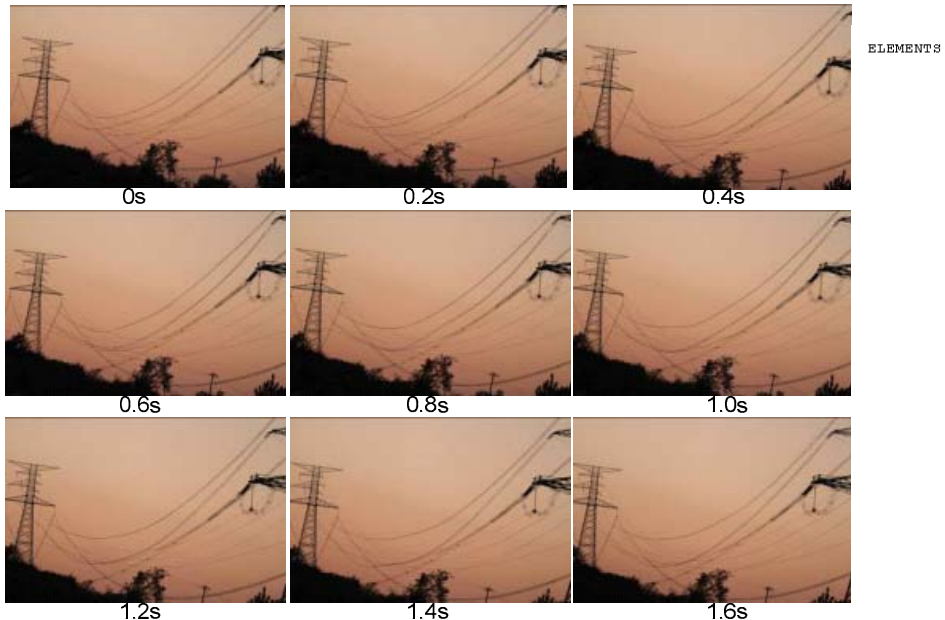

Fig. 3 Continuous shooting pictures of \#2-\#3 dual split line dancing

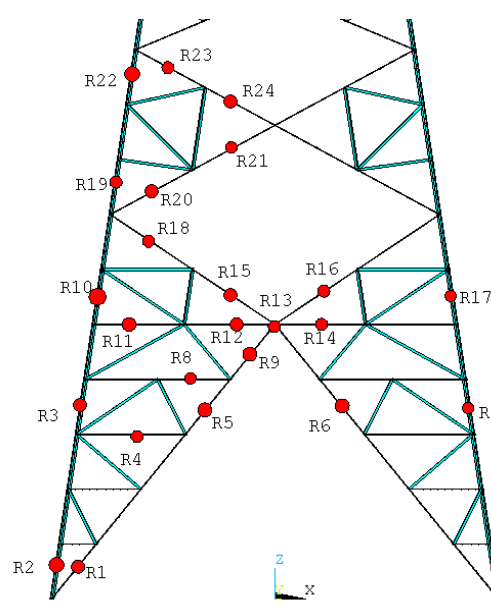

$\mathbf{N N}$

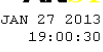

Fig.4 Strain gauge layout program of the transmission tower

\section{Test results and comparison}

A 24-channel synchronous power transmission tower strain measurement system has been established in this paper, 24 stress patches are arranged in the transmission tower, Stress changes of each position are acquisited when external conditions change. Figures 5 and 6 show the 10th and the 17 th strain curves of two measuring points respectively.

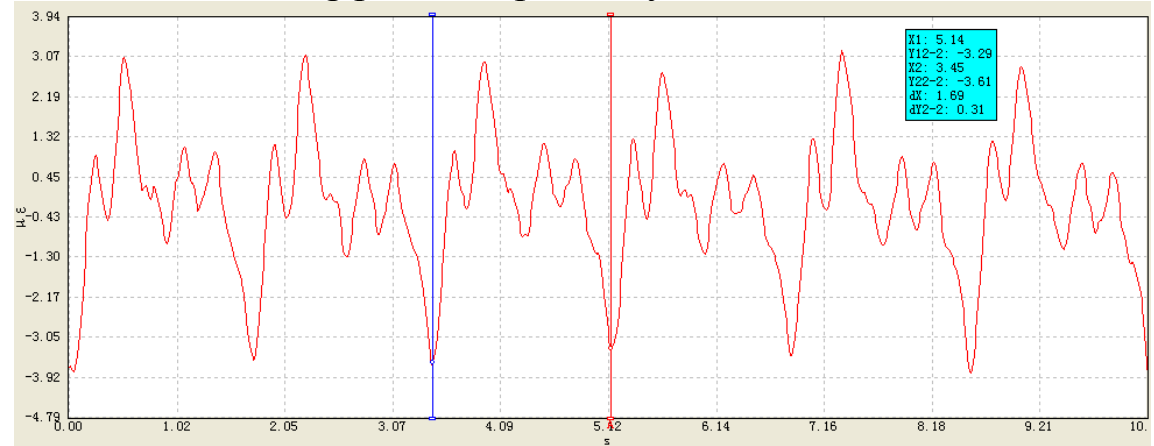

Fig.5 Strain curve of the $10^{\text {th }}$ measuring point

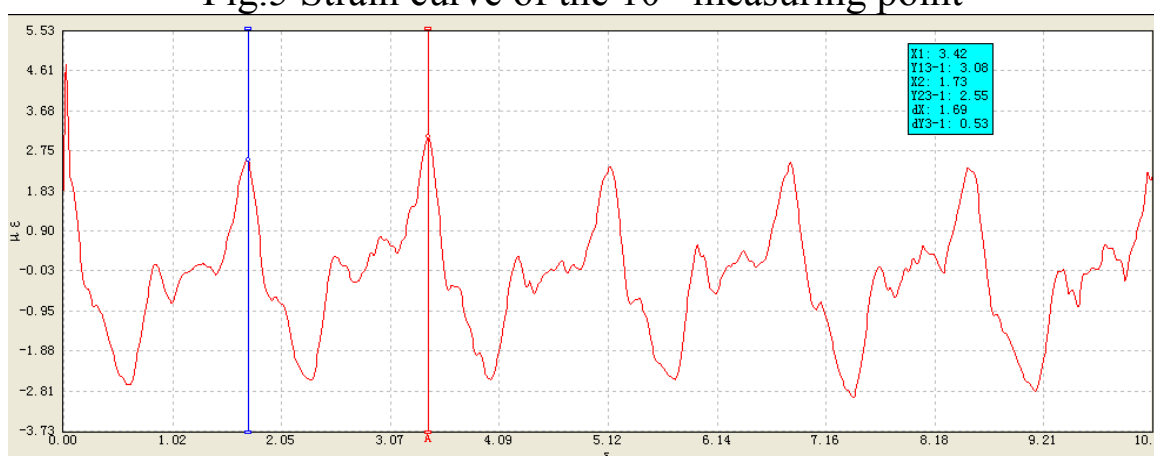

Fig.6 Strain curve of the 17 th measuring point

The measured strain of the each measuring point is shown in Table 1. Section webs of the transmission tower withstand greater stress; the cross timber at the bottom of transmission tower bears a greater stress. Special attention should be given to these points.

The $3^{\text {rd }}$ and the $4^{\text {th }}$ measuring point strain data of the transmission tower are collected by monitoring system in Figure 7 . The stress strain value of the 3 rd patch is less than the $4^{\text {th }}$ under the same load conditions. Therefore, strain of the transmission tower webs is relatively large under wind loads, special attention is Required in the design of transmission towers. 
Table. 1 the value of all measure point

\begin{tabular}{cccccccc}
\hline $\begin{array}{c}\text { Measuring } \\
\text { Point }\end{array}$ & $\begin{array}{c}\text { Maximum } \\
\text { of } \\
\text { Measured } \\
\text { Strain } \\
(\mu \xi)\end{array}$ & $\begin{array}{c}\text { Peak of } \\
\text { Measured } \\
\text { Strain } \\
(\mu \xi)\end{array}$ & $\begin{array}{c}\text { Stress State } \\
(\text { Mpa })\end{array}$ & $\begin{array}{c}\text { Measuring } \\
\text { Point }\end{array}$ & $\begin{array}{c}\text { Maximum } \\
\text { of } \\
\text { Measured } \\
\text { Strain } \\
(\mu \xi)\end{array}$ & $\begin{array}{c}\text { Peak of } \\
\text { Measured } \\
\text { Strain } \\
(\mu \xi)\end{array}$ & $\begin{array}{c}\text { Stress State } \\
(\text { Mpa })\end{array}$ \\
\hline 1 & 183.13 & 312.4 & 71 & 13 & -26 & 73.86 & 16.79 \\
2 & 122.97 & 216.33 & 49.16 & 14 & -63.54 & 139.15 & 31.62 \\
3 & 61.22 & 111.22 & 25.27 & 15 & 41.1 & 104.16 & 23.67 \\
4 & 206.25 & 269.39 & 61.22 & 16 & -8.53 & 74.93 & 17.03 \\
5 & 34.34 & 83.87 & 19.06 & 17 & 3.57 & 97.42 & 22.14 \\
6 & 170.05 & 229.97 & 52.26 & 18 & 109.59 & 267.76 & 60.85 \\
7 & 196.32 & 300.96 & 63.46 & 19 & 73.89 & 157.49 & 35.79 \\
8 & -12.46 & 279.22 & 279.22 & 20 & 95.52 & 184.59 & 41.95 \\
9 & -12.46 & 61.41 & 13.96 & 21 & 266.89 & 336.68 & 76.52 \\
10 & -14.70 & 84.08 & 19.11 & 22 & 258.3 & 353.23 & 80.28 \\
11 & 189.06 & 346.56 & 78.76 & 23 & 243.1 & 349.76 & 79.49 \\
12 & -29.13 & 80.85 & 18.38 & 24 & 389.49 & -89.6 & 108.88 \\
\hline
\end{tabular}

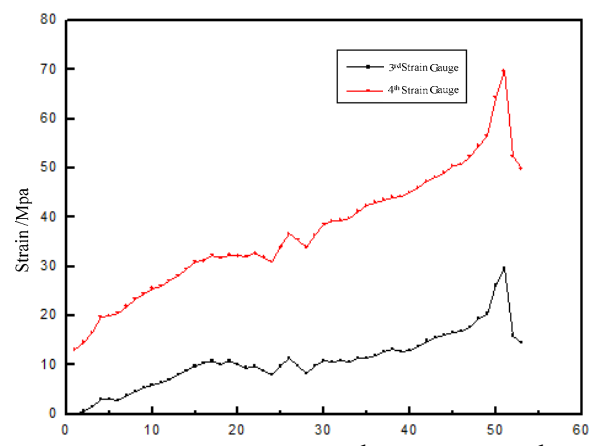

Fig.7 Comparison on the $3^{\text {rd }}$ and the $4^{\text {th }}$ strain data

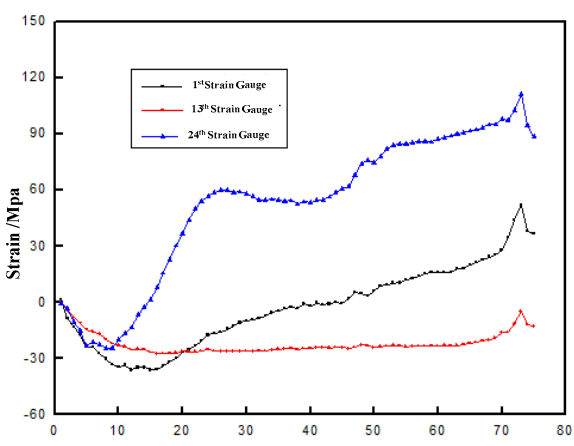

Fig.8 Strain in different regions

The $1 \mathrm{st}$, the $13^{\text {th }}$ and the $24^{\text {th }}$ measuring point strain data of the transmission tower are collected by a certain period of time strain monitoring system, as shown in figure 8 . The stress strain value of the $24^{\text {th }}$ patch is larger than the $1^{\text {st }}$ under the same load conditions. The stress strain value of the 1 st patch is larger than the $13^{\text {th }}$. The $24^{\text {th }}$ measuring point and he $1^{\text {st }}$ measuring point are more sensitive to environmental loads, the strain change greatly with the environmental loads changes. The $13^{\text {th }}$ measuring point is relatively stable, does not vary dramatically with the load and environment change.

The strain data of the $23^{\text {rd }}$ and the $24^{\text {th }}$ measurement points are collected by transmission tower strain monitoring system and compared during the period of 15:00 on March 282013 to 3:20 on March 29, 2013 in Figure 9. The strain value of the $24^{\text {th }}$ measuring point is always higher than the value of $23^{\text {th }}$. Special treatment is needed in the transmission towers design.

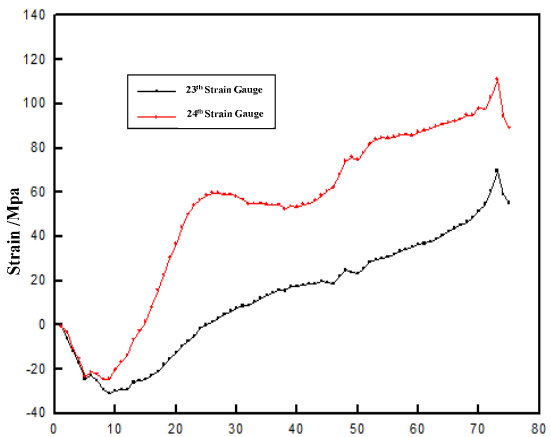

Fig. 9 Comparison on the $23^{\text {th }}$ and the $24^{\text {th }}$ strain data

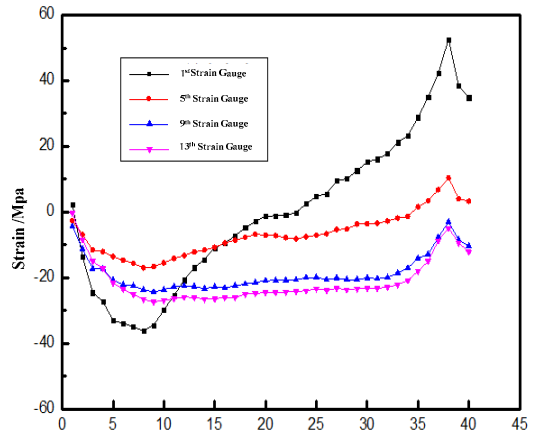

Fig.10 strain value of measure point on the foot of tower 
The $5^{\text {th }}$, the $9^{\text {th }}$ and the $13^{\text {th }}$ measuring point strain data of the transmission tower are collected and shown in figure 10 . The maximum strain values is the $1^{\text {st }}$ measuring point, the $5^{\text {th }}$ strain measurement point follows, the minimum strain values are the $9^{\text {th }}$ and the $13^{\text {th }}$ measuring point.

The $5^{\text {th }}$, and the $6^{\text {th }}$ measuring point strain data of the transmission tower are collected and shown in figure 11 . The $12^{\text {th }}$, and the $14^{\text {th }}$ measuring point strain data of the transmission tower are collected and shown in figure 12 . The wind direction of the base is northeast during the test, the $6^{\text {th }}$ measuring point located on the west side of the tower, the stress strain value of the $6^{\text {th }}$ patch is almost always greater than the $5^{\text {th }}$. Similarly, the stress strain value of the $14^{\text {th }}$ patch is almost always greater than the $12^{\text {th }}$. Thus, the impact of wind direction on the transmission tower strain is limited.

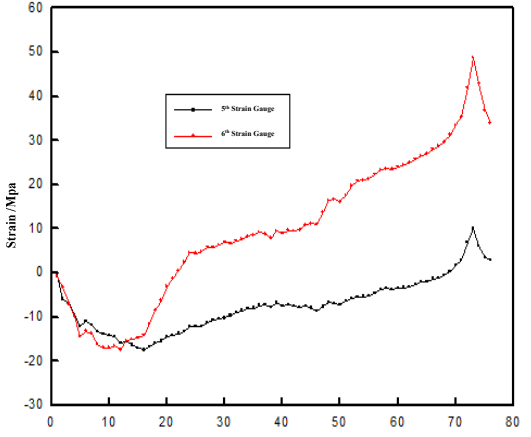

Fig. 11 the influence of wind direction to strain of transmission tower

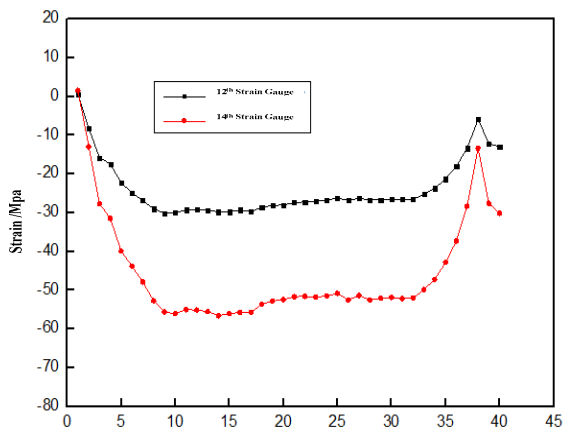

Fig. 12 Comparison on the $12^{\text {th }}$ and the $14^{\text {th }}$ strain data

\section{Summary}

1. The connection of the tower bottom and tower body expose more stress than the other regions, it is necessary to measuring this region, to obtain key locations of the transmission tower when strain changes under different load;

2. The lower part section 2-3 structure of the high-voltage transmission tower is the weakest part, should be considered when designing transmission tower.

3. The wind direction at each point transmission towers has some reflects on the strain, but impact limited, the effect of the wind direction should be considered during transmission tower structure design in specific regions.

\section{References}

[1] Liu Xin, Zhoushan 370m tower pole field trials and results analysis [D] Anhui: Hefei University of Technology, 2010.

[2] Zhaogui Feng, Xie Qiang Liang pivot fruit, and so on. Experimental study of wind tunnel design high voltage transmission line system, [J] 2009,35 (5): 1206-1213.

[3] Bell Miles, filling Lun Wu, Wang Wei, et al. Based on the principle of high pressure damping energy transmission tower wind vibration suppression method [J] Central South University, 2013,44 (1): 397-402.

[4] Li Li, Yin Peng, Wang Kaiming, and so on. Datong wind angle under dynamic wind Span Transmission Wind Vibration Response Analysis, [J] Wuhan University of Technology, 2009,31 (23): 68-72.

[5] Liu Zhenya. UHV grid [M]. Beijing: China Electric Power Press, 2005: 360-374. 